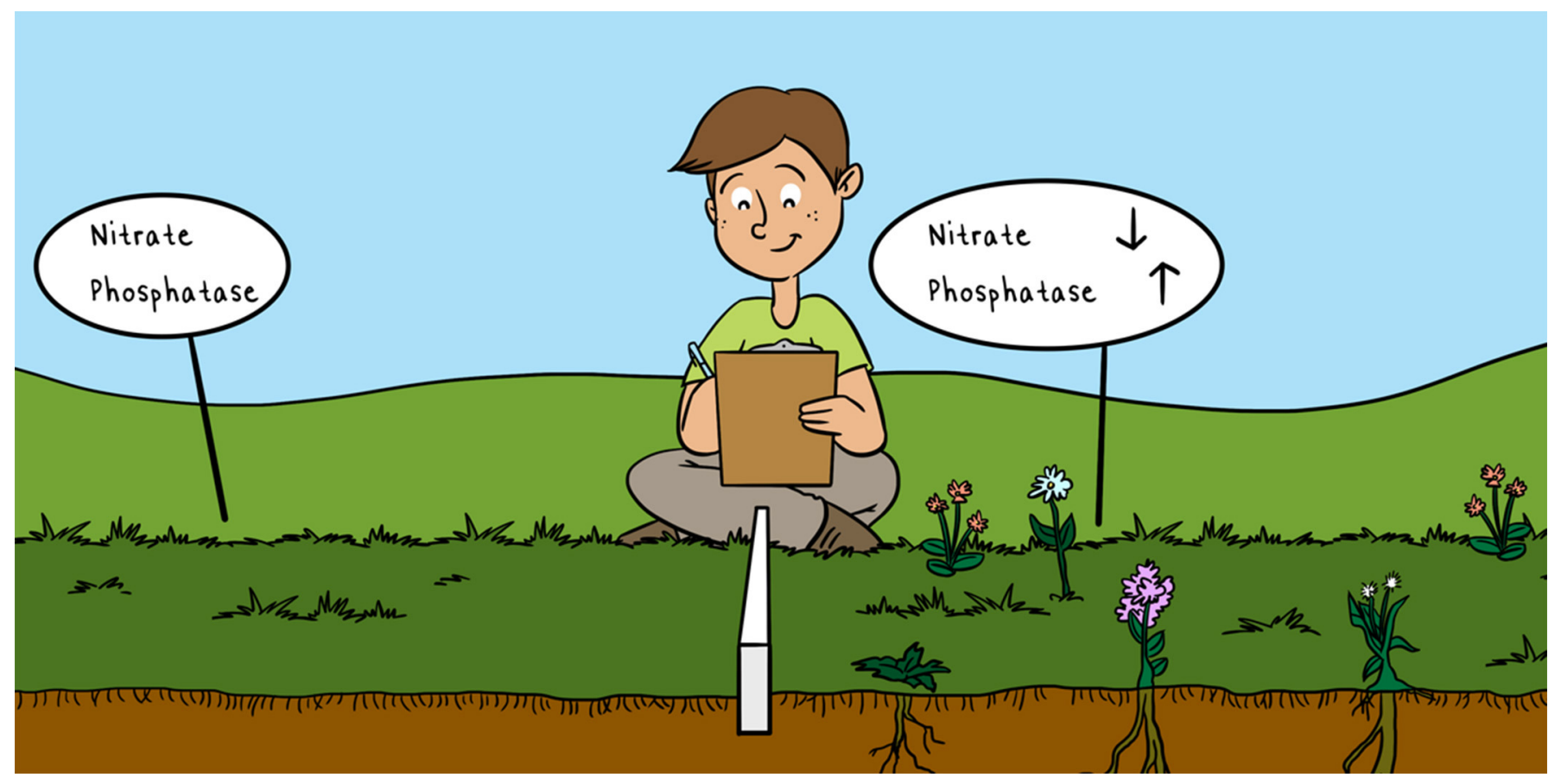

\title{
DOES PLANT BIODIVERSITY INFLUENCE NUTRIENT CYCLES?
}

\section{Eva Koller-France $^{1 *}$, Wolfgang Wilcke ${ }^{2}$ and Yvonne Oelmann ${ }^{1}$ \\ ${ }^{1}$ Department of Geography/Geoecology, University of Tübingen, Tübingen, Germany \\ ${ }^{2}$ Institute for Geography and Geoecology, Karlsruhe Institute of Technology, Karlsruhe, Germany}

\section{YOUNG REVIEWERS:}

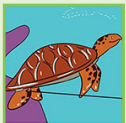

MACKENZIE

AGE: 14

ROSE

AGE: 14
All living things, like humans, animals, plants, and even microbes, need to take up the same nutrient elements to live, most importantly nitrogen and phosphorus. Understanding the cycling of these elements through the ecosystem is one key to understanding why ecosystems work the way they do. One of the questions we are asking is if the diversity of organisms, like plants or insects, is related to these nutrient cycles. When plant communities are made up of many different plant species, they seem to make better use of the available soil nutrients than plant communities made up of fewer species. This may be because of something called complementarity, which means different plant species access the available nutrients in different ways, for example from different soil depths. In this article, we will describe the connections between plant biodiversity and soil nutrient cycling and discuss the implications for the functioning of the whole ecosystem. 


\section{WHY DO WE CARE ABOUT BIODIVERSITY EFFECTS ON NUTRIENT CYCLES?}

All living things on earth need certain nutrient elements. In natural ecosystems, these nutrients, most importantly nitrogen and phosphorus, are taken up by plants from the soil. Plants may then be eaten by animals or people. The nutrients are returned to the soil through animal droppings and when plants and animals die, and then can be taken up again by new plants. Because everything repeats on and on, we call this the nutrient cycle.

In different ecosystems and under different environmental conditions, the cycling of nutrients can work faster or slower, and nutrients can be used and recycled by different parts of the system in more or less complete ways, which may cause imbalances. For example, sometimes there are more available nutrients than are needed because farmers add too much fertilizer to the soil, or because there is a warm day in winter when tiny organisms in soil recycle and release nutrients from dead material which are not needed by plants during their inactive phase. If there are excess nutrients in the soil, those nutrients may be washed out into the groundwater or into lakes and streams. From there, they are transported to bigger rivers and finally to the sea. If these water bodies receive too great an amount of nutrients, there can be rapid growth of algae, which damages freshwater ecosystems. In this case, too much of a good thing can definitely be a big problem. This is why studying the nutrient cycles of ecosystems under different conditions is not just a good way of learning how ecosystems work, but also helps us with practical considerations, such as how to protect our supply of clean water.

\section{BIODIVERSITY}

Simply put, the number of species in an ecosystem.
We know that the biodiversity, the richness of species, of an ecosystem plays a role in many of its functions, and we also know that biodiversity is decreasing on a global scale. For example, some species of bees and rare flowers are going extinct, and therefore many ecosystems are now less diverse than they previously were. This is one of the reasons we are interested in how the nutrient cycle responds to changes in biodiversity.

\section{WHAT EFFECT DOES BIODIVERSITY HAVE ON NITROGEN IN SOIL?}

A connection between biodiversity and nitrogen (in the form of nitrate, one form of nitrogen that is taken up by plants) in soil has been fairly well-established in experiments studying the effects of biodiversity on ecosystems [1]. In these experiments, plant diversity is studied by creating small model ecosystems (often grasslands, where this is easiest to do) with a known number of species growing under the same environmental conditions, for example in the same field. This is done by sowing a specific mixture of seeds into a square of ground, called 


\section{BIOMASS}

The total amount of mass present in components of the ecosystem, such as plants or animals. For example, plant biomass, which we talked about in this article, can be defined as all the living matter contained in the plant roots, shoots, leaves, flowers, and fruits. In temperate climate, biomass is not constant but usually increases from spring to late summer and decreases in autumn. the experimental plot. These small plots are regularly checked for plants that were not sown into them, which are removed. Results from experimental plots with higher or lower diversity can be compared to each other quite well, since the only difference between plots should be the number of species growing on them.

In these experiments in grasslands, we find that the higher the number of plant species, the lower the concentration of nitrogen in soil, which is fairly easy to explain. If plants take up more nitrogen, this means that less is "left over" in the soil. In ecosystems that are reasonably rich in nutrients, this also means less nitrogen is washed out into ground water, which protects ground water quality and freshwater ecosystems.

To understand these results, we must consider one of the other important effects of plant biodiversity on unfertilized ecosystems, which is an increase in plant growth. When there is higher plant biodiversity, there is generally more plant biomass, for example more hay on meadows, being produced. More nitrogen is needed to build this greater amount of biomass. Of course, another way of looking at it is that this greater biomass can only be built if the plants can access more nitrogen (and all other necessary nutrients). This is where something called complementarity comes into play.

\section{DIFFERENT SPECIES WORK TOGETHER TO ACCESS NUTRIENTS}

Complementarity describes a mechanism by which different parts of an ecosystem (such as different species) use different essential (and limited) resources from different locations or at different times. The use of this resource by one species "complements" that of the other species. In this way, the plant community uses the available resources more completely. In our example, the resource used is soil available nitrogen. You probably know that plants take up nutrients from the soil with their roots. But not all roots are the same. Some plants have strong, long roots that can access deeper parts of the soil, but do not branch out much on their way there. Others have roots that only reach shallower parts of the soil. If you combine even just these two types, you can see that one plant species takes water and nutrients out of the shallow soil, and the other takes the same resources out of the deeper soil (Figure 1). The two types of root systems complement each other, and this means that the nutrients that would have gone unused in a system that only contained one or the other of these plants are now being used to produce more plant biomass, which serves as food for microbes and animals. These two plants use different niches in space, which we call spatial niches. Similarly, not all plants develop and grow at the same time. If one species develops early in the spring and another only starts growing in summer, then these two species will not take up most of their nutrients at the same time. They use 
Figure 1

Complementarity between

rooting systems in soil systems under higher biodiversity leads to more efficient nutrient cycling. Broad arrows represent greater uptake of nitrate or higher phosphatase activity in more diverse ecosystems; narrow arrows represent less uptake of nitrate or lower phosphatase activity in less diverse ecosystems. While nitrate is being taken up by the roots and transported into the above-ground parts of the plant, phosphatase is released downwards into the soil to make phosphate available for uptake by roots.

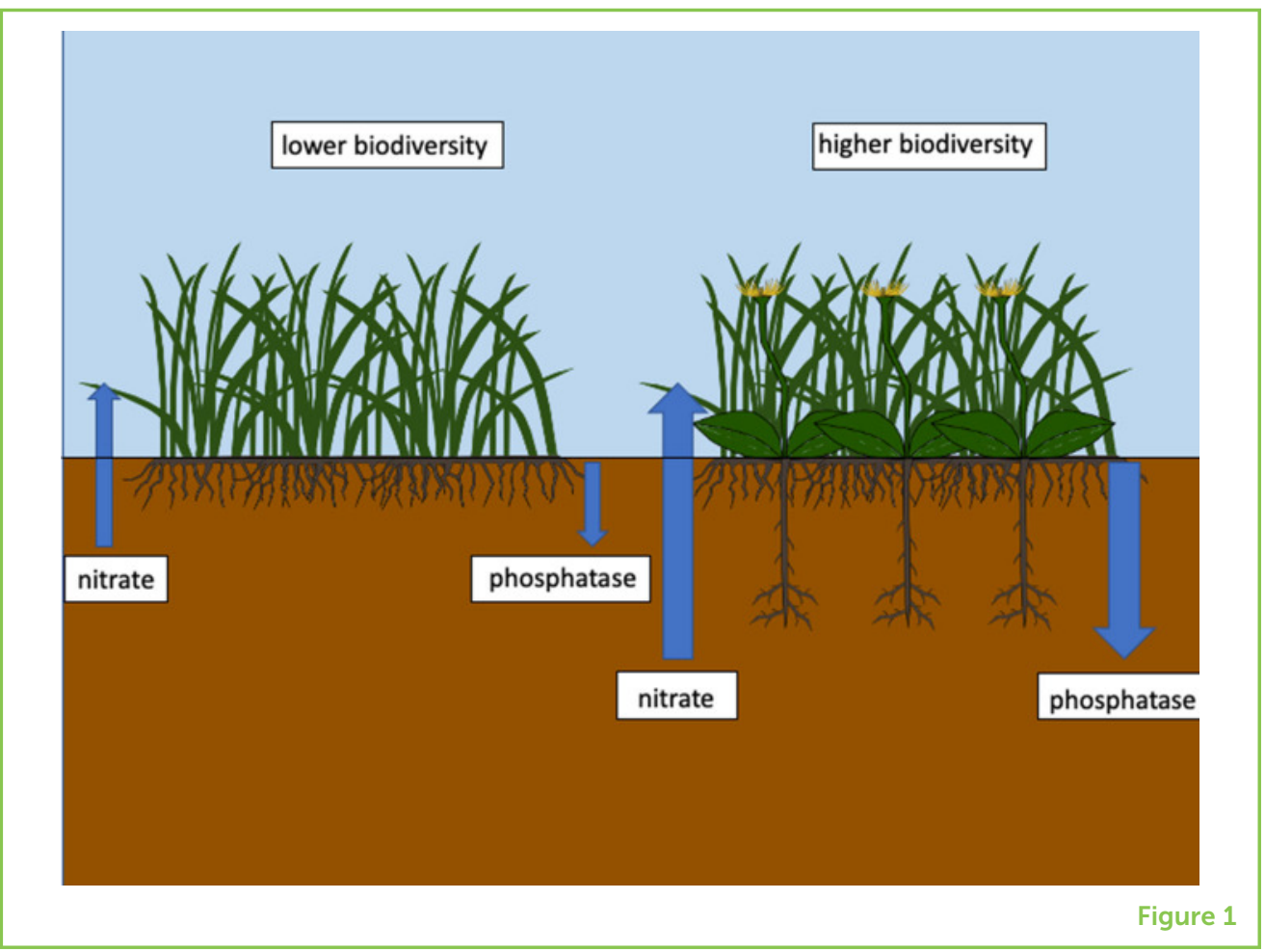

two temporal niches, or niches in time, and they too access nutrients and other resources much more completely together than they would alone. So, when not only two but many plants grow together using different spatial and temporal niches, the nitrogen in soil is used more completely, and therefore, less is left in the soil for us to measure.

\section{PLANT BIODIVERSITY AND SOIL PHOSPHORUS}

It would be logical to assume that the effect of biodiversity we have just described for soil nitrogen is the same for soil phosphorus. Both are essential nutrient elements, and both can be limiting to biomass production. However, perhaps surprisingly at first, this is not something we find in biodiversity experiments, in which we control the species richness of single ecosystems to study biodiversity effects on these ecosystems. Often, concentrations of readily available phosphate, the chemical form of phosphorus that is taken up by plants, are so low in the soils of the systems we study that there simply cannot be any "leftovers" as is sometimes the case with nitrogen. So, does plant diversity have any effect on phosphorus cycling at all?

The short answer is yes, probably. We know that there is more phosphorus in the plant biomass of more diverse systems and this effect-similar to nitrogen-is caused by the greater amount of biomass that comes from a greater phosphorus uptake by plants [2]. The question is how more diverse ecosystems can take up more phosphate, even though we cannot see the results of this in the soil. 


\section{ENZYME}

Small molecules that speed up a (bio-)chemical reaction in or outside of cells.

\section{ECOSYSTEM}

\section{PRODUCTIVITY}

The amount of organic material, such as plant biomass, produced by the ecosystem in a given time. A good example for this would be how much wheat or hay is harvested in the course of 1 year from a field.

To access phosphate in the soil, both plants and microbes use enzymes (substances that facilitate certain chemical reactions) to split phosphate from more complex chemical molecules that exist in soil humus, the organic part of the soil you likely know as compost. We can measure the speed and function of phosphatase, the enzyme responsible for making phosphate accessible in this way, which allows us to estimate how much phosphate is being released from the soil for plant or microbial use. In ecosystems where plant biodiversity is higher, we find more activity in soil phosphatases (Figure 1) [3]. This indicates that, while we cannot see the higher uptake of phosphorus from soils with higher plant biodiversity the same way we can for nitrogen, we can see that there is more efficient access to phosphorus in soils through higher phosphatase activity. This is one way plant biodiversity can influence phosphorus cycling through the ecosystem.

\section{THE IMPORTANCE OF BIODIVERSITY FOR ECOSYSTEM FUNCTION}

So, what does all this mean? The general assumption is that with continued global changes, more species will be lost from ecosystems and biodiversity will continue to decline. With the decline of biodiversity, it is likely that both nitrogen and phosphorus cycling will become less efficient, that is, ecosystems will be less capable of keeping and recycling nitrogen and phosphorus than they are now. This is a big change in the ecosystem and may be one factor leading to a reduction of ecosystem productivity. Declining biodiversity may also lead to nutrients being lost from the system, such as nitrate being washed out into the groundwater. Excess nitrate is a pollutant if it gets into our drinking water and it can also have negative effects on the aquatic ecosystems it is transported to, for example through the excessive growth of algae. And at the other end, these nutrients are then not available to plants, microbes or animals in the original ecosystem, leaving a system that is likely poorer in nutrients and less capable of sustaining the organisms living in it.

\section{REFERENCES}

1. Oelmann, Y., Buchmann, N., Gleixner, G., Habekost, M., Roscher, C., Rosenkranz, $\mathrm{S}$., et al. 2011. Plant diversity effects on aboveground and belowground $\mathrm{N}$ pools in temperate grassland ecosystems: development in the first 5 years after establishment. Glob. Biogeochem. Cycles 25. doi: 10.1029/2010gb003869

2. Oelmann, Y., Richter, A. K., Roscher, C., Rosenkranz, S., Temperton, V. M., Weisser, W. W., et al. 2011. Does plant diversity influence phosphorus cycling in experimental grasslands? Geoderma 167:178-87. doi: 10.1016/j.geoderma. 2011.09.012

3. Hacker, N., Ebeling, A., Gessler, A., Gleixner, G., Macé, O. G., Kroon, H., et al. 2015. Plant diversity shapes microbe-rhizosphere effects on $P$ mobilisation from organic matter in soil. Ecol. Lett. 18:1356-65. doi: 10.1111/ele.12530 
SUBMITTED: 30 April 2020; ACCEPTED: 02 March 2021;

PUBLISHED ONLINE: 14 April 2021

EDITED BY: Malte Jochum, German Centre for Integrative Biodiversity Research (iDiv), Germany

CITATION: Koller-France E, Wilcke W and Oelmann Y (2021) Does Plant

Biodiversity Influence Nutrient Cycles? Front. Young Minds 9:557532. doi: 10.3389/

frym.2021.557532

CONFLICT OF INTEREST: The authors declare that the research was conducted in the absence of any commercial or financial relationships that could be construed as a potential conflict of interest.

COPYRIGHT @ 2021 Koller-France, Wilcke and Oelmann. This is an open-access article distributed under the terms of the Creative Commons Attribution License (CC BY). The use, distribution or reproduction in other forums is permitted, provided the original author(s) and the copyright owner(s) are credited and that the original publication in this journal is cited, in accordance with accepted academic practice. No use, distribution or reproduction is permitted which does not comply with these terms.

\section{YOUNG REVIEWERS}

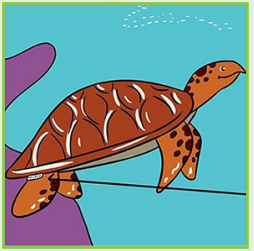

\section{MACKENZIE, AGE: 14}

My name is Mackenzie, and I enjoy music (both playing and listening), books (fantasy in particular), and sports (my favorite is tennis). I also enjoy science, math, and language, but the thing I enjoy most is backpack camping.

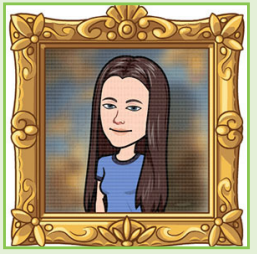

ROSE, AGE: 14

Hello. I am 14 years old and live in Canada. I like knitting, crocheting, and reading.

\section{AUTHORS}

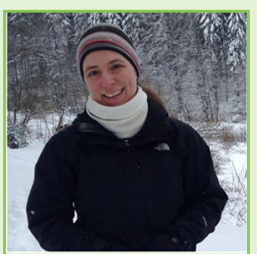

\section{EVA KOLLER-FRANCE}

Eva is an ecosystem ecologist interested in the effects of all kinds of global changes on ecosystem carbon and nutrient cycling. She spent her formative Ph.D. years wandering the Arctic to study the effects of environmental change on the links between carbon and nutrient cycles, and she is now a post-doctoral researcher for the Jena Experiment (http://www.the-jena-experiment.de/), studying the long-term effects of plant species richness on nitrogen and phosphorus cycling. *ekoller@gmail.com 


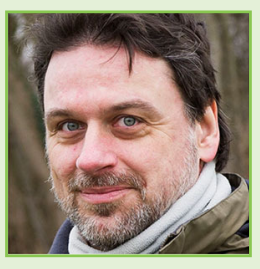

\section{WOLFGANG WILCKE}

Wolfgang Wilcke studied Geoecology at the University of Bayreuth and is now Professor of Geomorphology and Soil Science at the Karlsruhe Institute of Technology (KIT) after research and teaching stations at the TU Berlin, the Johannes Gutenberg University Mainz and the University of Berne. His research interests focus on the effects of environmental change, including climate change, land-use change, nutrient deposition, pollution, and biodiversity loss, on the element cycling between soils and plants. He uses soil chemical analyses, long-term observations of element fluxes, and stable isotope approaches.

\section{YVONNE OELMANN}

Yvonne is a soil scientist working on ecosystem carbon and nutrient cycling. She did her Ph.D. at the TU Berlin on the effects of plant diversity on nutrient cycling in grassland soils (http://www.the-jena-experiment.de/). As a Post-Doc, she broadened her perspective on this issue by focusing on complex forest ecosystems and by including the impact of mankind. She was appointed a professorship at the University of Tübingen in 2011 and since then has been working on carbon and nutrient cycling in grasslands and forests around the globe. 